\title{
Editorial
}

\section{Reconnecting to the Biosphere: a Social-Ecological Renaissance}

\author{
Carl Folke $^{1,2}$ and Lance Gunderson ${ }^{3}$
}

\section{INTRODUCTION}

The biosphere, the sphere of life, is the living part of the outermost shell of our rocky planet, the part of the Earth's crust, waters, and atmosphere where life dwells. It is the global ecological system integrating all living beings and their relationships. People and societies are embedded in the biosphere, depending on the functioning and life support it provides, while shaping it globally. We have now entered the Anthropocene era, the era in which the magnitude and impact of human actions have become a powerful planetary force, modifying the biosphere at the scale of the globe. Humanity in this new situation needs to understand its role and responsibility as a dominant force in the operation of the biosphere, start accounting for and governing natural capital, and actively foster societal development in tune with the planet of which we are part. It is time to reconnect to the biosphere.

Clearly, global environmental change interacts with interdependent and globalizing human societies. In the globalized world, there are no ecosystems without people and no people who do not depend on ecosystem functioning. They are inextricably intertwined in a new play of interdependent social-ecological systems. Ecosystem services therefore are not really generated by nature but by social-ecological systems. Economic progress is largely founded on nature's capacity for production but rarely on resilience and renewal. Many now realize that dynamic and complex social-ecological systems require strategies that build resilience rather than attempt to control for optimal production and short-term gain under conditions assumed to be stable. That mustering social innovation and ingenuity for social-ecological transformations away from destructive pathways to sustainable ones creates exciting opportunities for societal development in tune with the biosphere.

We believe that humanity has entered a new renaissance period. This new era is a dramatic change from one that perceived people and nature as separate actors to one that sees them as interdependent social-ecological systems. The ongoing policy and science debates on climate change challenges contribute to reconnecting human actors to the biosphere. The renaissance is linked to the realization that social-ecological systems are dynamic and connected, from the local to the global, in complex webs of interactions subject to both gradual and abrupt changes. Also, part of the renaissance is the realization that complex problems require complex solutions that acknowledge and manage uncertainty of these systems, rather than use the uncertainty to hinder progress. That is one reason why the articles of this and other journals are critically important to debates at all scales.

\section{ISSUES 3 AND 4 OF 2012}

The papers of the past two issues of Ecology and Society are reflections of the ongoing shift. In contrast to the inertia of many university structures that continue to divide the world into the natural and social, with humanities as part of the latter, the contributions provide fresh attempts to explore, investigate, analyze, synthesize, and integrate across these artificial disciplinary divides by interpreting and combining diverse ways of knowing for understanding and action. Indeed, we as editors believe that such integrated approaches are very much needed and have the potential to really capture what is going on in the real interconnected social-ecological world of the Anthropocene.

To us, it is a privilege and rewarding to follow the emergence of integrative science for resilience and sustainability, from pioneering efforts to new collaborative platforms and networks slowly diffusing into traditional disciplines. Who knows what might spring out of these efforts? In any case, we are amazed by the richness and novelty of the contributions ranging from conceptual papers on well-being, resilience, cross-scale interactions, and institutional interplay and fit, to case studies with diverse actors and networks, corporate social responsibility, adaptive management and governance and the law, cognition, and traditional ecological knowledge systems, belief systems, and alternative cosmologies applied to stewardship of freshwater, fisheries, marine ecosystems, coral reefs, forests and rainforests, savannas, rural communities, and urban areas.

Our Associate Editor-in-Chief, Marco Janssen, coordinates the "The Science and Practice of Ecology and Society Award." This award is given annually to the individual or organization that is the most effective in bringing transdisciplinary science of the interactions of ecology and society into practice. This fall, the subject editors of the journal voted and selected the paper by Xiaoli Shen and Jiaxin Tan entitled; Ecological conservation, cultural preservation, and a bridge between: the journey of Shanshui Conservation Center in the Sanjiangyuan region, Qinghai-Tibetan Plateau, China. as the recipient of the 2012 Science and Practice Award. We congratulate the authors for their contribution to the journal and for receiving this award. 


\section{SPECIAL FEATURES}

The last two issues of 2012 continue the trend of publishing a substantial percentage of articles in special features. These features have become a hallmark of the journal, and we encourage such contributions to continue because they are developing and capturing new ways to confront the multifaceted dimensions of environmental issues. Over the past six months, six special features have been completed:

1. A Systems Approach for Sustainable Development in Coastal Zones

2. Mental Models in Human - Environment Interactions: Theory, Policy Implications, and Methodological Explorations

3. Balancing Ecology and Community using Cumulative Effects Models

\section{The Privilege to Fish}

5. Urban Ecological and Social-Ecological Research in the City of Cape Town

6. Sustainability Impact Assessment of Forest Management Alternatives in Europe

Another twelve special features are in progress and dominate the home page of the journal. The topics range from socialecological assessments of oil spills to multifaceted governance to new approaches in natural resource management. We invite the reader to explore these contributions to interdisciplinary scholarship.

The success of running a peer-reviewed journal rests on the professional support of many. First of all, we thank the invaluable subject editors carefully selected and invited to help us ensure the standard of the journal, and then the referees, wrestling with the manuscripts, committed to improving the works to secure quality, then, the group of hard working copy editors, and finally, our great team that manages the journal, who are on top of everything, instantly and continuously. Thanks a lot for your remarkable efforts.

We, as editors, look forward to continue to receive exciting submissions and will do our best to have Ecology and Society further the vision of reconnecting humans to the biosphere through the social-ecological play.

Responses to this article can be read online at: http://www.ecologyandsociety.org/issues/responses. php/5517 